\title{
Molecular Docking study of COVID-19 Main Protease with Clinically Approved Drugs
}

\section{Tachoua Wafa* and Kabrine Mohamed}

*Corresponding author: Tachoua Wafa.

*Benyoucef Benkhedda University, Nature and Life Sciences department, Didouche Mourad, 16000, Algiers, Algeria.

University of Science and Technology Houari Boumediene, Faculty of Biological Sciences, Cellular and Molecular Biology, BP 32, El-Alia Bab Ezzouar, 16111, Algiers, Algeria.

E-mail: wtachoua@yahoo.fr

E-mail: mohamed.kabrine@gmail.com

\section{Running: MOLECULAR DOCKING}

Key words: Coronavirus, COVID-19 Main protease, Molecular docking, SwissDock, Approved drugs. 


\section{INTRODUCTION}

The outbreak of the novel coronavirus infection, disease, COVID-19, caused by the new coronavirus 2019-nCoV that is now officially designed as severe acute respiratory syndrome related coronavirus SARS-CoV-2, represents a pandemic threat to global public health $[1,2]$. On January 30, the World Health Organization (WHO) announced a Public Health Emergency of International Concern (PHEIC) for the 2019-nCoV outbreak [3].

Coronaviruses are relatively large virus containing a single stranded positive-sense RNA genome encapsulated within a membrane envelope. The viral membrane is studded with glycoprotein spikes that give coronaviruses their crown-like appearance. There are four classes of coronavirus designed as alpha, beta, gamma and delta. The beta-coronavirus class included severe acute respiratory syndrome (SARS) virus (SARS-CoV), Middle East Respiratory Syndrome (MERS) virus (MERS-CoV), and the COVID-19 causative agent named SARS-CoV-2 [4]. Although SARS-CoV-2 is classified into beta-coronviruses group, it is diverse from MERS-CoV and SARS-CoV. It has been reported that SARS-CoV-2 genes share less than $80 \%$ nucleotides identity with SARS-CoV and it is more transmissible than other SARS-CoV viruses [5, 6, 7].

The SARS-CoV-2 genome encodes several structural proteins such as the glycosylated spike $(\mathrm{S})$ protein, envelop protein $(\mathrm{E})$, membrane protein $(\mathrm{M})$, nucleocapsid protein $(\mathrm{N})$. In addition, the viral genome also encodes numerous nonstructural proteins, including RNA-dependant RNA polymerase (RdRp), coronavirus main protease $\left(\mathrm{CoV} \mathrm{M}^{\mathrm{pro}}\right)$ and papaine-like protease (PLpro). Upon entrance to the host cell, the viral genome is released and subsequently translated into viral polyproteins using host cell translation machinery, which are cleaved into effector proteins by viral proteases PLpro and $\mathrm{CoV} \mathrm{M}^{\text {pro }}[8,9]$. This last protease, play a critical role in the virus replication process. Therefore, it is a potential target for anticoronaviruses screening [10].

The recently released crystal structure of the $\mathrm{M}^{\text {pro }}$ of COVID-19 (6Lu7) was obtained by a cocrystallization with a peptide like inhibitor called N3 (PRD_002214). This enzyme forms a dimer whose each monomer comprises three domains: Domain I (residues 1-101) and II (102184) consists of an antiparallel beta barrel, and the alpha helical domain III (residues 201-301) is required for the enzymatic activity. This enzyme shares a similar structure with cysteine protease with an active site lacking the third catalytic residue, it comprises a catalytic dyad, namely Histidine 41 (H41) and Cysteine 145 (C145) [11].

Although, several molecular docking studies have been established to find a potential inhibitors of $\mathrm{M}^{\text {pro }}$ activity based on antiviral compounds commonly used to treat immunodeficiency virus (HIV), phytochemical or antimalarial agents $[12,13,14]$. To date no specific therapies for COVID-19 disease are available and investigations regarding the treatment of COVID-19 disease are lacking. In the following study, we investigate the $\mathrm{M}^{\text {pro }}$ inhibitory potential of eights clinically approved drugs belonging to four pharmacological 
classes: anti-viral, anti-bacterial, anti-infective and anti-histamine, using a molecular docking approach performed by the SwissDock bioinformatic tool.

\begin{abstract}
A novel strain of coronavirus, namely, Corona Virus Infection Disease 19 has been identified in Wuhan city of China in December 2019, continues to spread at a rapid rate worldwide. There are no specific therapies available and investigations regarding the treatment of this disease are still lacking. In order to identify a novel potent inhibitor we performed docking studies on the main virus protease with eight drugs belonging to four pharmacological classes: anti-malarial, anti-bacterial, anti-infective and anti-histamine. Among the eight studied compounds, Lymecycline and Mizolastine appear as potential inhibitors of this protease. These two compounds revealed a minimum binding energy of 8.87 and $-8.71 \mathrm{Kcal} / \mathrm{mol}$ with 168 and 256 binding modes detected in the binding substrate pocket, respectively. Lymecycline and Mizolastine interact with specific residues in substrate binding cavity. Thus, Lymecycline and Mizolastione may serve as a tool to fight COVID-19 disease. However, this data need further in vitro and in vivo evaluation to repurpose these two drugs against COVID-19 disease.
\end{abstract}




\section{METHODS}

\section{Target and ligand retrieval form databases}

This research is a descriptive-analytical study. In this study, the interaction of several approved compounds was investigated. A total of eight compounds was tested against COVID-19 main protease $\left(\mathrm{CoV} \mathrm{M}^{\mathrm{pro}}\right)$. $\mathrm{N} 3$ compound was used as a docking target for comparison.

In order to obtain the structure information of selected compounds, a Drugbank database (https://www.drugbank.ca/) was used (Table I) [15]. The structure of the new CoV $\mathrm{M}^{\text {pro }}$ mentioned in access number 6lu7 was retrieved from the PDB database (https://www.rcsb.org/) [16]. It corresponds to a complex between the enzyme and its inhibitor N3. The 6Lu7 structure preparation consists of deleting all water molecules and N3 inhibitor. The new file was saved for docking analysis.

$\mathrm{CoV} \mathrm{M}^{\text {pro }}$ (Residues 1-306 aa) is composed of three domains: Domain I (residues 8101), domain II (residues 102-184) and domain III (residues 201-303). The CoV $\mathrm{M}^{\text {pro }} \mathrm{S}$ enzymes share a highly conserved substrate-binding pocket, located in the cleft between domains I and II. This pocket serves as a drug target of our selected compounds (Figure 1) [11].

Table I: List of approved compounds used in this study.

\begin{tabular}{lllll}
\hline Compound & $\begin{array}{l}\text { Accession } \\
\text { number }^{\mathrm{a}}\end{array}$ & Description & $\begin{array}{l}\text { MM } \\
\mathrm{g} / \mathrm{mol}\end{array}$ & Class \\
\hline Chloroquine & DB00608 & Aminoquinolone derivative & 319.87 & Antimalarial \\
Quinine & DB00468 & Alkaloid & 324.41 & Antimalarial \\
Nitazoxanide & DB00507 & Thiazolide & 307.28 & Anti-infective \\
Doxycycline & DB00254 & Oxytertacycline derivative ATB & 444.43 & Antibacterial \\
Lymecycline & DB00256 & Tetracycline with a 7-chloro substitution & 602.63 & Antibacterial \\
Cetirizine & DB00341 & Histamine H1 antagonist & 388.88 & Antihistaminic \\
Mizolastine & DB12523 & Histamine H1 antagonist & 432.50 & Antihistaminic \\
Indinavir & DB00224 & Specific HIV protease inhibitor & 613.78 & Antiviral \\
\hline
\end{tabular}

a: Drug bank accession number, b: Antibiotic, MM: Molecular Mass 

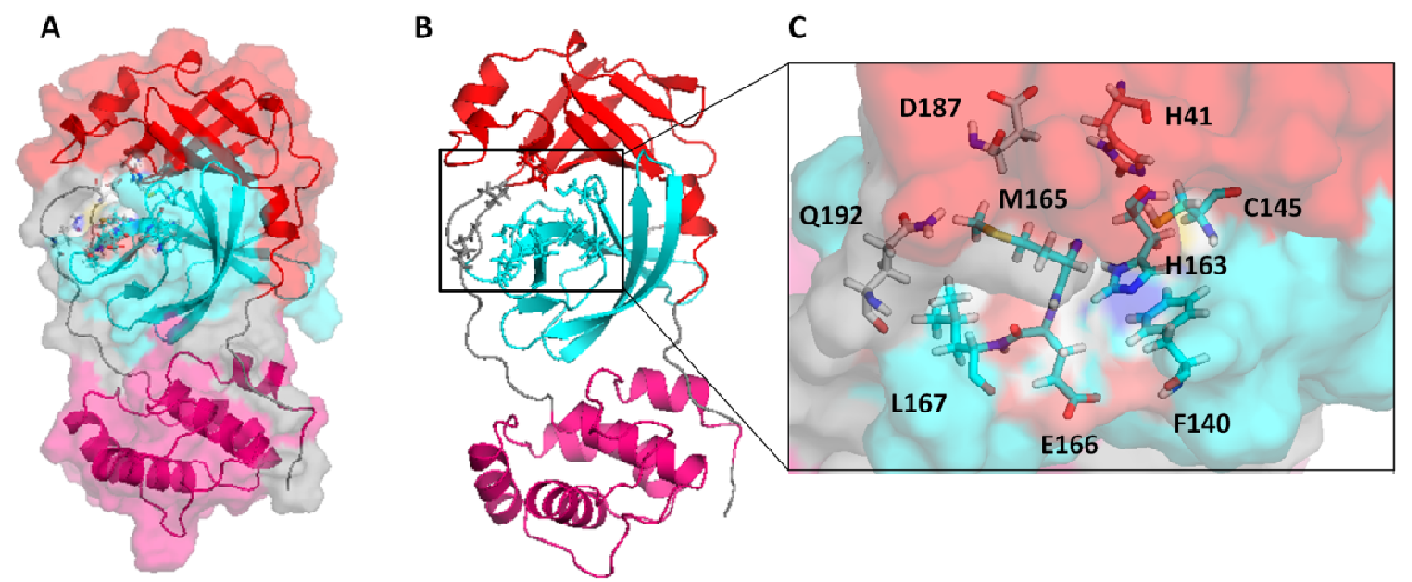

Figure 1: Pymol Structure representation of $\mathrm{CoV} \mathrm{M}^{\text {pro }}$. Surface (A) and Cartoon (B) representations of one protomer of the dimeric $\mathrm{CoV} \mathrm{M}^{\text {pro }}$. (C) Surface and stick representations of the conserved binding pocket of $\mathrm{CoV} \mathrm{M}^{\text {pro }}$. Red color: Cov $\mathrm{M}^{\text {pro }}$ domain $\mathrm{I}$, Bleu color: $\mathrm{CoV} \mathrm{M}^{\text {pro }}$ domain II and pink color for $\mathrm{CoV} \mathrm{M}^{\text {pro }}$ domain III. Gray color represents coils. C(Cys), D(Asp), E(Glu), F(Phe), H(His), L(Leu), M(Met), Q(Gln).

\section{Blind Docking}

In order to investigate the molecular interaction between several approved compounds and COVID-19 main protease $\left(\mathrm{Cov} \mathrm{M}^{\mathrm{pro}}\right)$, blind docking was performed using a SwissDock server (http://www.swissdock.ch/). This program was run under accurate mode with no flexibility of the side chain of any amino acid of the target protein. In addition, a binding pocket was not defined so as not to bias the docking towards the active site. The protein and ligand were specified by uploading PDB and Mol2 files, respectively. After submission, an email was sent to user's email address containing a direct link to access docking results.

SwissDock generates all possible binding modes for each ligand and the most favorable binding modes at a given pocket were clustered. All ligand clusters were saved in an output file called "prediction file". The prediction file provided; Cluster rank, Element, Fulfitness and estimated binding free energy $(\Delta \mathrm{G})$. A cluster corresponds to a predicted binding pocket on the target protein and the cluster rank represents the different 
conformations of a ligand in a certain cluster [17]. Only the lowest energy model of cluster zero was considered to be the most favorable interaction.

\section{Clusters visualization}

After docking, Chimera, Pymol softwares and Protein Ligand Interaction profiler (PLIP) server were used to visualize the receptor ligand interactions for the lowest energy model of cluster obtained from the previous step. Each cluster for every ligand was inspected for amino acids interacting with the ligand, hydrogen bonds (H-bonds), the specific atoms involved. All the interacting amino acids with the target were noted for each cluster $[18,19$, 20].

\section{Binding pocket prediction}

Although the binding site is well characterized for $\mathrm{N} 3$ inhibitor within many CoV $\mathrm{M}^{\text {pro }}$ crystals. We have applied the DoGSiteScorer online tool (https://proteinsplus.zbh.unihamburg.de/\#dogsite) to predict and describe binding pockets within native $\operatorname{Cov} \mathrm{M}^{\text {pro }}$ and the complexes Cov $\mathrm{M}^{\mathrm{pro}}$ /inhibitors obtained after docking analysis.

DoGSiteScorer is a grid-based method which uses a Difference of Gaussian filter to detect potential binding pockets solely based on the 3D structure of the protein and splits them into subpockets. Global properties, describing the size, shape and chemical features of the predicted (sub) pockets are calculated. Per default, a simple druggability score is provided for each (sub) pocket, based on a linear combination of the three descriptors describing volume, , surface, hydrophobicity and enclosure. Furthermore, a subset of meaningful descriptors is incorporated in a support vector machine (libsvm) to predict the (sub) pocket druggability score (values are between zero and one). The binding pockets are ranked according to their size, surface area and druggability score [21]. 


\section{RESULTS}

In order to investigate the possible mechanism by which selected drugs act, an silico theoretical molecular docking approach was used.

The eight approved drugs (Chloroquine, Quinine, Nitazoxanide, Doxycycline, Lymecycline, Cetirizine, Mizolastine, and Indinavir) were able to bind $\mathrm{CoV} \mathrm{M}^{\text {pro }}$, with a binding energies of $-9.71,-8.09,-7.71,-7.52,-8.87,-7.99,-8.71,-9.81 \mathrm{Kcal} / \mathrm{mol}$, respectively (Table II, column 5). These drugs were able to bind to $\mathrm{CoV} \mathrm{M}^{\text {pro }}$ and hence may contradict its function. Indeed, these compounds fit in the same binding pocket (Figure 2). Indinavir, Chloroquine, Lymecycline and Mizolastine seem to have the best energies of binding -9.81, 9.71, -8.87 and $-8.71 \mathrm{Kcal} / \mathrm{mol}$, respectively. In addition, N3 compound revealed a better binding energy of $-10.83 \mathrm{Kcal} / \mathrm{mol}$ which was obvious because this compound is well characterized $\mathrm{CoV} \mathrm{M}^{\text {pro }}$ inhibitor (Table II, column 5).

According to a fullfitness score, Lymecycline and Mizolastine had the more favorable binding mode, which is indicated by a more negative fullfitness score -1332.56 and -1300.12 $\mathrm{Kcal} / \mathrm{mol}$, respectively (Table II, column 4). In addition, docking results produced 33 clusters of ligand Lymecycline around the complete $\mathrm{CoV} \mathrm{M}^{\text {pro }}$ protein. Analysis of these clusters showed that 23 of these clusters were able to bind in the substrate binding cavity. These clusters together contained a total of 168 elements out of 256 predicted elements. Furthermore, it was observed that N3, Indinavir, Chloroquine and Mizolastine showed that all clusters were able to fit into $\mathrm{CoV} \mathrm{M}^{\text {pro }}$ binding pocket (Table II, column 2).

Although Lymecycline and Doxycycline belong to the same family of tetracyclines, Lymecycline bind more effectively to $\mathrm{CoV} \mathrm{M}^{\text {pro }}$ with a minimum energy of $-8.87 \mathrm{Kcal} / \mathrm{mol}$ compared to Doxycycline with $-7.52 \mathrm{Kcal} / \mathrm{mol}$ binding energy (Table II, column 5).

To investigate the possible reasons for differences in the binding energies, we examined the formed complexes with Pymol and Protein Ligand Interaction Profiler (PLIP) tools. Table II showed the number and length of H-bonds formed between the target protease and the different compounds. Chloroquine, Nitazoxanide and Cetirizine established only one H-bonds with N142, E166 and N142 residues, respectively. Otherwise, Quinine, Doxycycline and Indinavir were found to form two H-bonds with E166, E166 and (L141, Gly143) residues, respectively. Interestingly, Mizolastine and Lymecycline were found to form three H-bonds with Cov $\mathrm{M}^{\text {pro }}$. Indeed, Lymecycline established three specifics H-bounds (two H-bonds with E166 residue and one H-bond with Q189 residue) and a salt bridge with E166 (Figure 3A, B and C). However, Mizolastine formed three H-bonds (two H-bonds with T24 residue and one with G143 residue) and two hydrophobic interactions with T25 and E166 residues (Figure 4A, $\mathrm{B}$ and $\mathrm{C})$.

In order to elucidate and describe Lymecycline binding pocket, Dogsitescorer server was used to analyze Lymecycline/6Lu7, Mizolastine/6Lu7 and N3/6Lu7 complexes. Table III reported the first three pocket of each complex and those of 6Lu7 protease crystal structure. Results revealed that N3, Lymecycline and Mizolastione occupied the same pocket (P0) with a high druggability score of 0.8 and a volume of $1191.74,1061.18$, and $1266.18 \AA^{3}$, 
respectively. In addition, Lymecycline and Mizolastine seem to be close to the active H41 residue in comparison with $\mathrm{N} 3$ which is extremely close to H41 (Figure 5D, E and F).

Based on Docking and Dogsitescorer studies, it has been clearly expressed that Lymecycline and Mizolastine showed favorable binding with the new $\mathrm{CoV} \mathrm{M}^{\text {pro }}$, and the results seem comparable with those of $\mathrm{N} 3$ compound.

Table II: Molecular docking analysis results for several drugs against 6Lu7 crystal structure. These drugs were ranked according to their minimum binding energy. The lowest energy model of cluster rank zero was considered.

\begin{tabular}{|c|c|c|c|c|c|c|c|}
\hline Compound & Clusters & $\begin{array}{l}\text { Total } \\
\text { elements }\end{array}$ & $\begin{array}{l}\text { Fullfitness } \\
\text { (Kcal/mol) }\end{array}$ & $\begin{array}{l}\Delta \mathrm{G} \\
(\mathrm{Kcal} / \mathrm{mol})\end{array}$ & H-bonds & $\begin{array}{l}\text { Length } \\
(\AA)\end{array}$ & Residues \\
\hline \multirow{2}{*}{ N3 } & \multirow{2}{*}{$38 / 38$} & \multirow{2}{*}{$256 / 256$} & \multirow{2}{*}{-1172.91} & \multirow{2}{*}{-10.83} & \multirow{2}{*}{2} & 2.1 & G143 \\
\hline & & & & & & 2.8 & Q189 \\
\hline \multirow{2}{*}{ Indinavir } & \multirow{2}{*}{$54 / 54$} & \multirow{2}{*}{$256 / 256$} & \multirow{2}{*}{-1098.93} & \multirow{2}{*}{-9.81} & \multirow{2}{*}{2} & 2.7 & L141 \\
\hline & & & & & & 2.6 & G143 \\
\hline Chloroquine & $44 / 44$ & $254 / 254$ & -1223.94 & -9.71 & 1 & 2.6 & N142 \\
\hline \multirow{3}{*}{ Lymecycline } & \multirow{3}{*}{$23 / 33$} & \multirow{3}{*}{$168 / 256$} & \multirow{3}{*}{-1332.56} & \multirow{3}{*}{-8.87} & \multirow{3}{*}{3} & 2.2 & E166 \\
\hline & & & & & & 2.3 & E166 \\
\hline & & & & & & 2.9 & Q189 \\
\hline \multirow{3}{*}{ Mizolastine } & \multirow{3}{*}{$54 / 54$} & \multirow{3}{*}{$256 / 256$} & \multirow{3}{*}{-1300.12} & \multirow{3}{*}{-8.71} & \multirow{3}{*}{3} & 2.3 & G143 \\
\hline & & & & & & 2.5 & T24 \\
\hline & & & & & & 2.1 & 124 \\
\hline Quinine & $39 / 40$ & $242 / 250$ & -1135.13 & -8.09 & 2 & 2.6 & E166 \\
\hline Cetirizine & $38 / 42$ & $224 / 256$ & -1112.62 & -7.99 & 1 & 2.1 & N142 \\
\hline Nitazoxanide & $58 / 64$ & $224 / 256$ & -1215.20 & -7.77 & 1 & 2.1 & E166 \\
\hline Doxycycline & $22 / 32$ & $176 / 256$ & -1276.83 & -7.52 & 2 & $2 / 2.4$ & E166 \\
\hline
\end{tabular}

Column 2 represents clusters within $\operatorname{Cov} \mathrm{M}^{\text {pro }}$ binding pocket/total clusters

Column 3 represents number of conformations within $\mathrm{CoV} \mathrm{M}^{\text {pro }}$ binding pocket/Total elements

E(Glu), G(Gly), L(Leu), N(Asn), Q(Gln), T(Thr). 

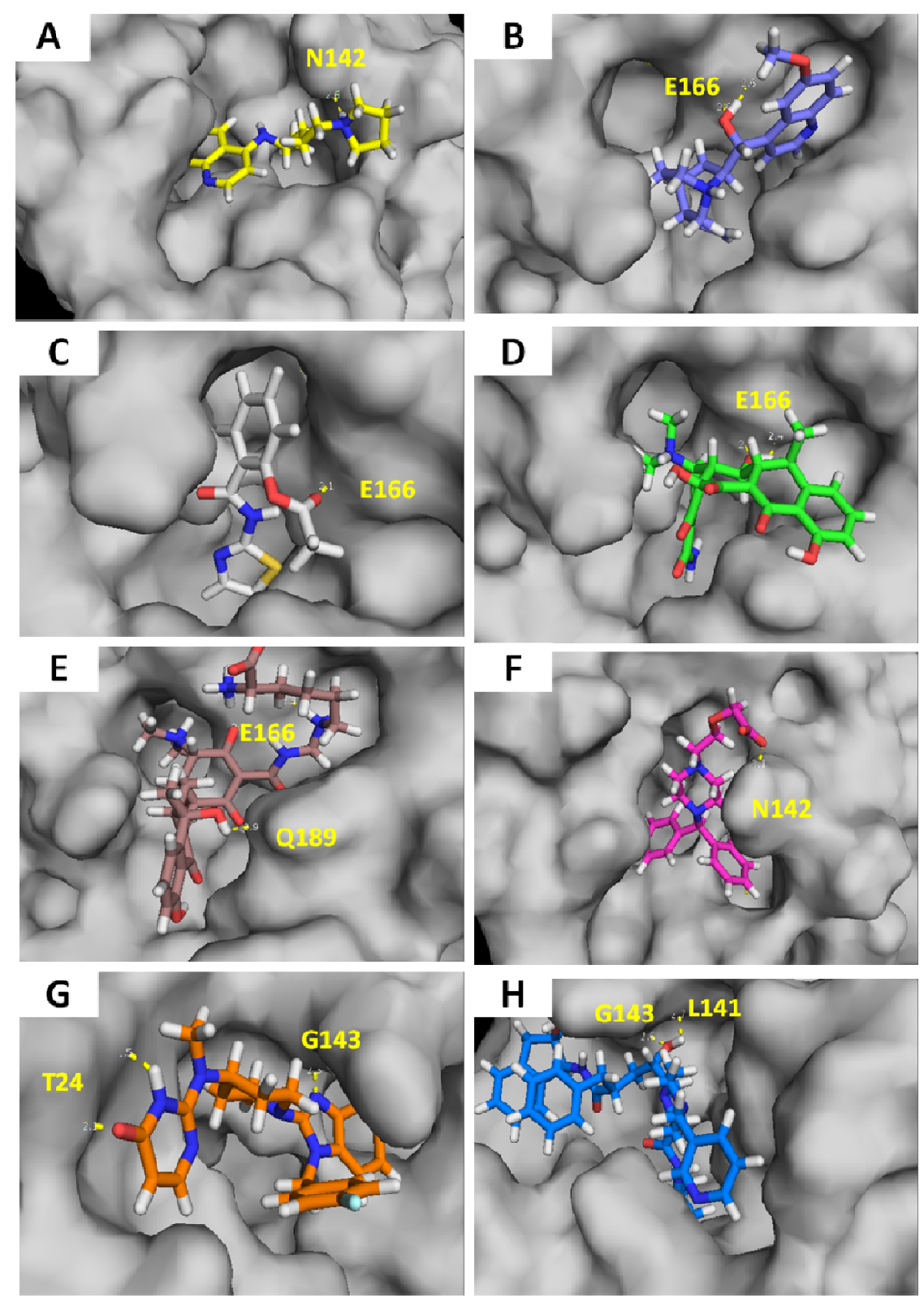

Figure 2: Docking poses of different drugs against $\mathrm{CoV} \mathrm{M}^{\text {pro }}$ visualized by Pymol. The protease $\mathbf{M}^{\text {pro }}$ is shown as gray background, inhibitors are in different colors. (A) Chloroquine. (B) Quinine. (C) Nitazoxanide. (D) Doxycycline. (E) Lymecycline. (F) Cetirizine. (G) Mizolastine. (H) Indinavir. H-bonds are represented by yellow dashed line. Interacting residues are labeled: E (Glu), G (Gly), H (His), L (Leu), N (Asn), Q (Gln), T (Thr). 

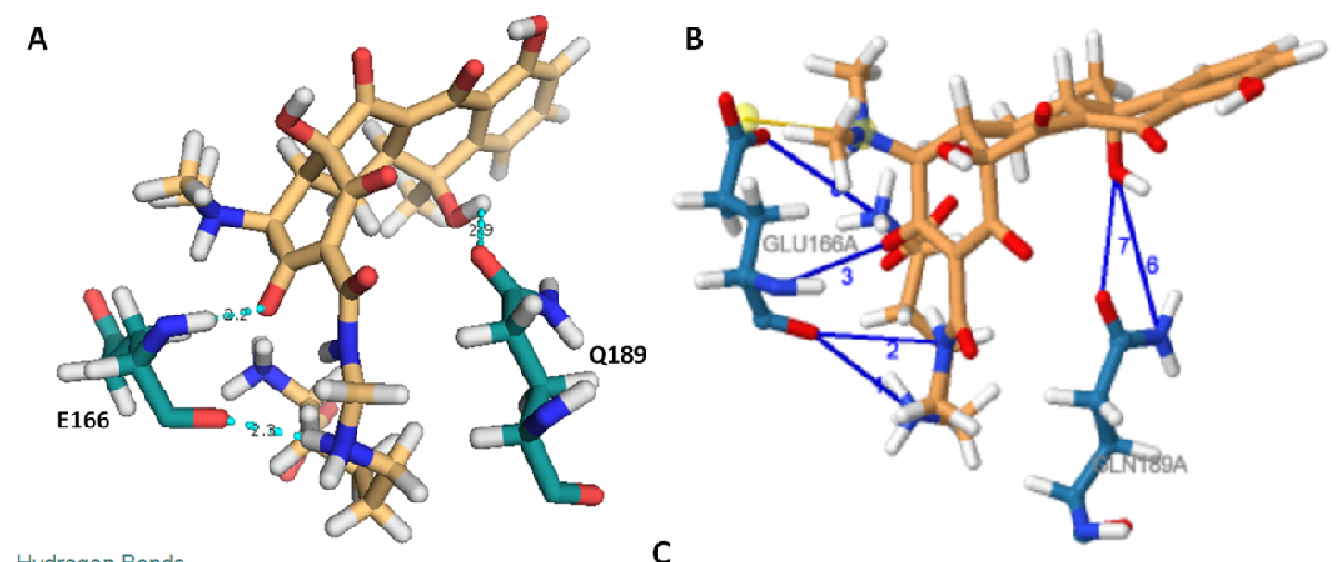

\begin{tabular}{|c|c|c|c|c|c|c|}
\hline \multicolumn{3}{|c|}{ Hydrogen Bonds } & \multicolumn{4}{|c|}{ C } \\
\hline Index & Residue & $A A$ & Distance $\mathrm{H}-\mathrm{A}$ & Distance D-A & Donor Angle & Protein donor? \\
\hline 1 & $166 \mathrm{~A}$ & GLU & 2.29 & 3.21 & 148.34 & $x$ \\
\hline 2 & $166 \mathrm{~A}$ & GLU & 3.09 & 3.63 & 114.48 & $\mathbf{x}$ \\
\hline 3 & $166 \mathrm{~A}$ & GLU & 2.23 & 3.12 & 146.95 & $\checkmark$ \\
\hline 4 & $166 \mathrm{~A}$ & GLU & 3.30 & 3.67 & 106.31 & $\checkmark$ \\
\hline 5 & $166 \mathrm{~A}$ & GLU & 3.00 & 3.67 & 123.96 & $\mathbf{x}$ \\
\hline 6 & $189 \mathrm{~A}$ & GLN & 3.32 & 4.01 & 128.57 & $\checkmark$ \\
\hline 7 & $189 \mathrm{~A}$ & GLN & 2.87 & 3.31 & 109.12 & x \\
\hline \multicolumn{7}{|c|}{ Salt Bridges .... } \\
\hline Index & Residue & $A A$ & Distance Pro & otein positive? & Ligand Group & Ligand Atoms \\
\hline 1 & $166 \mathrm{~A}$ & GLU & 4.66 & & Tertamine & 4691 \\
\hline
\end{tabular}

Figure 3: Interactions established after docking of Lymecycline with $\mathrm{CoV} \mathrm{M}^{\text {pro }}$ protease. (A) Pymol visualization of hydrogen bonds (Cyan dashed lines) between Lymecycline and CoV $\mathrm{M}^{\text {pro }}$ conserved residues (E166 and Q189). (B) Visualization of $\mathrm{CoV} \mathrm{M}^{\text {pro }} /$ Lymecycline complex interactions using Protein Ligand Interaction Profiler (PLIP). Lymecycline drug is represented in orange while interacting amino acids are represented in blue. (C) Detailed information of interactions between Lymecycline and $\mathrm{CoV} \mathrm{M}^{\text {pro }}$ obtained by PLIP. Solid bleu lines depict H-bonds, while salt bridge interaction is represented by a yellow dashed line. Interacting amino acids are labeled: E 166 (Glu 166), Q189 (Gln 189). 


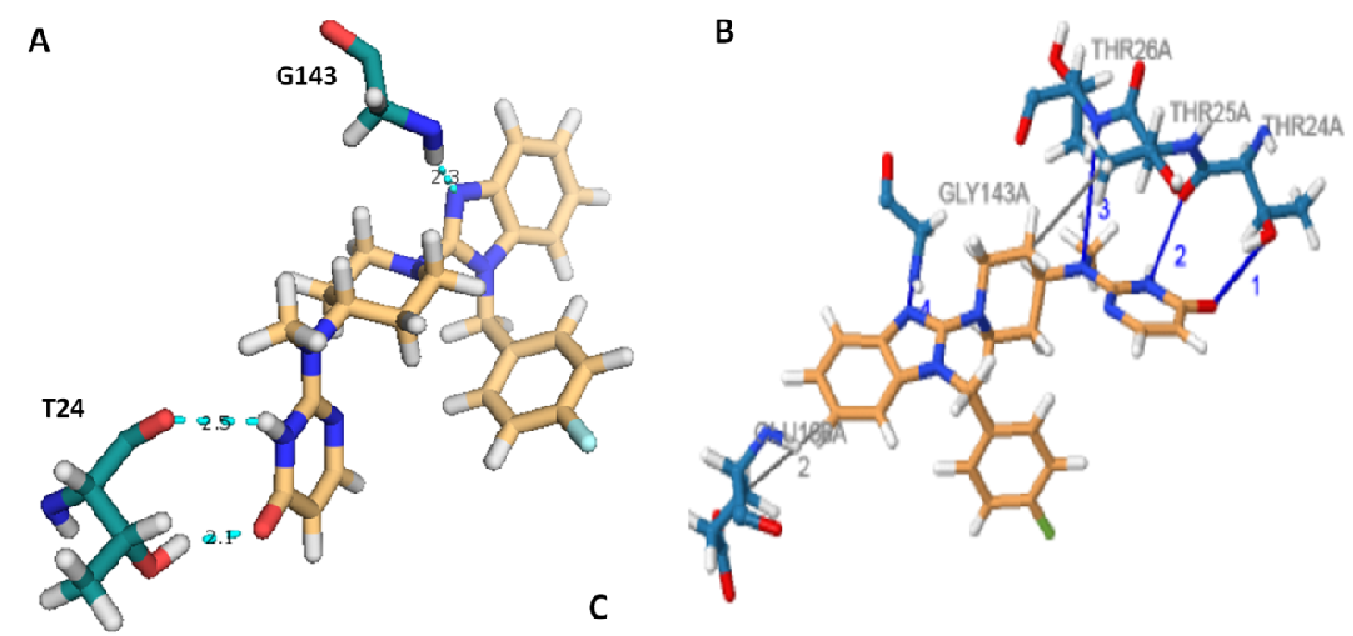

\begin{tabular}{l|llllll|}
\hline Hydrophobic Interactions & $\cdots .$. & & \\
\hline \hline Index & Residue & AA & Distance & Ligand Atom & Protein Atom \\
\hline 1 & $25 \mathrm{~A}$ & THR & 3.81 & 4715 & 357 \\
\hline 2 & $166 \mathrm{~A}$ & GLU & 3.91 & 4695 & 2546 \\
\hline
\end{tabular}

\begin{tabular}{|c|c|c|c|c|c|c|c|c|c|}
\hline Index & Residue & $\mathrm{AA}$ & Distance H-A & Distance D-A & Donor Angle & Protein donor? & Sidechain & Donor Atom & Acceptor Atom \\
\hline 1 & $24 \mathrm{~A}$ & THR & 2.06 & 2.86 & 139.14 & $\checkmark$ & $v$ & 341 [03] & 4707 [O2] \\
\hline 2 & $24 \mathrm{~A}$ & THR & 2.48 & 3.23 & 129.59 & $x$ & $x$ & 4689 [N3] & 348 [O2] \\
\hline 3 & $26 \mathrm{~A}$ & THR & 3.15 & 4.10 & 158.32 & $\checkmark$ & $x$ & 363 [Nam] & 4706 [N3] \\
\hline 4 & $143 \mathrm{~A}$ & GLY & 2.33 & 3.29 & 161.49 & $\checkmark$ & $x$ & 2216 [Nam] & 4691 [N2] \\
\hline
\end{tabular}

Figure 4: Interactions established after docking of Mizolastine with $\mathrm{CoV} \mathrm{M}^{\text {pro }}$ protease. (A) Pymol visualization of hydrogen bonds (Cyan dashed lines) between Mizolastine and CoV $\mathrm{M}^{\mathrm{pro}}$ residues T24 and G143. (B) Visualization of $\mathrm{CoV} \mathrm{M}^{\mathrm{pro}} /$ Mizolastine complex interactions using Protein Ligand Interaction Profiler (PLIP). Mizolastine drug is represented in orange while interacting amino acids are represented in blue. (C) Detailed information of interactions between Mizolastine and $\mathrm{CoV} \mathrm{M}^{\text {pro }}$ obtained by PLIP. Solid bleu lines depict H-bonds, while hydrophobic interaction is represented by a gray dashed line. Interacting amino acids are labeled: T24 (Thr 24), G143 (Gly 143). 
Table III: Binding pockets prediction for chain A of $\mathrm{CoV} \mathrm{M}^{\text {pro }}$ with their inhibitors.

\begin{tabular}{|c|c|c|c|c|c|c|}
\hline Structure & $\begin{array}{l}\text { Pocket } \\
\text { Number }\end{array}$ & $\begin{array}{l}\text { Volume } \\
\left(\AA^{3}\right)\end{array}$ & $\begin{array}{l}\text { Surface } \\
\left(\AA^{2}\right)\end{array}$ & Drug score & $\begin{array}{l}\text { Hydrophobicity } \\
\text { ratio }\end{array}$ & Enclosure \\
\hline \multirow[t]{3}{*}{$6 \mathrm{Lu} 7$} & $\overline{0}$ & 702.27 & 842.81 & 0.77 & 0.35 & 0.13 \\
\hline & 1 & 374.59 & 757.16 & 0.74 & 0.48 & 0.11 \\
\hline & 2 & 330.18 & 518.79 & 0.56 & 0.40 & 0.24 \\
\hline \multirow[t]{3}{*}{$6 \mathrm{Lu} 7+\mathrm{N} 3$} & 0 & 1191.74 & 1136.13 & 0.8 & 0.34 & 0.1 \\
\hline & 1 & 257.79 & 538.69 & 0.56 & 0.43 & 0.08 \\
\hline & 2 & 253.7 & 544.53 & 0.51 & 0.49 & 0.24 \\
\hline \multirow[t]{3}{*}{ 6Lu7+Lymecycline } & $\mathbf{0}$ & 1061.18 & 1032.51 & 0.8 & 0.35 & 0.08 \\
\hline & 1 & 292.67 & 475.29 & 0.51 & 0.39 & 0.25 \\
\hline & 2 & 277.7 & 601.59 & 0.65 & 0.47 & 0.1 \\
\hline \multirow[t]{3}{*}{ 6Lu7/Mizolastine } & $\mathbf{0}$ & 1266.18 & 1294.39 & 0.8 & 0.32 & 0.09 \\
\hline & 1 & 272.13 & 514.16 & 0.64 & 0.34 & 0.1 \\
\hline & 2 & 272.06 & 488.48 & 0.5 & 0.49 & 0.24 \\
\hline
\end{tabular}




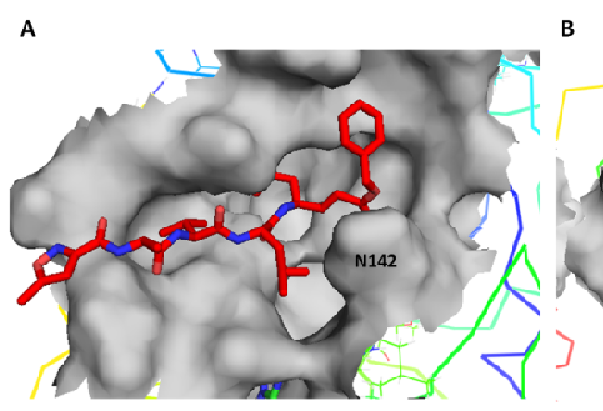

B

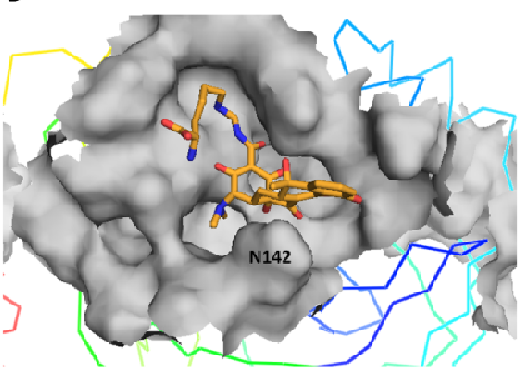

D

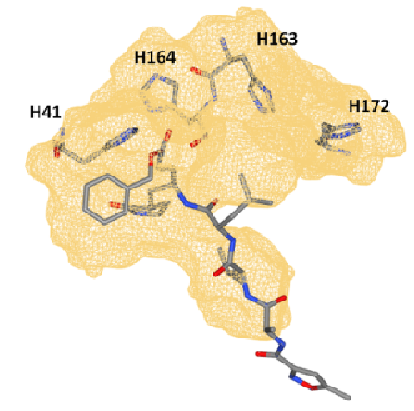

E

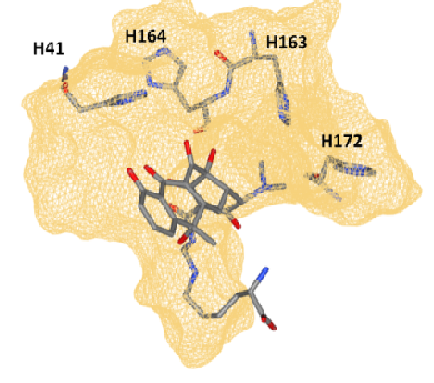

C

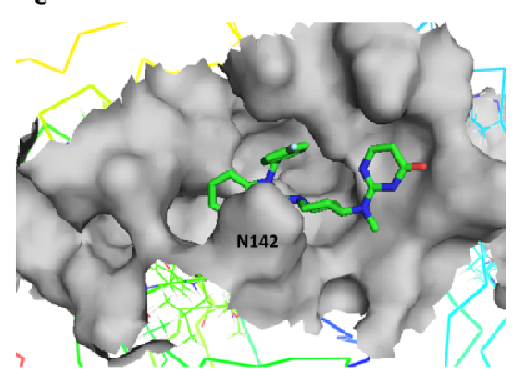

F

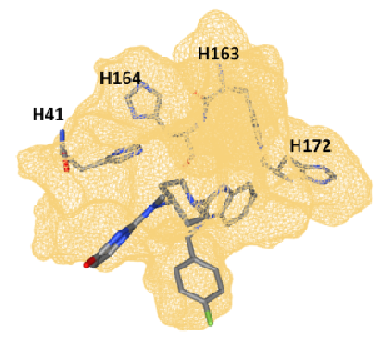

Figure 5: Comparison of predicted binding pockets between compound N3, Lymecycline and Mizolastine. Pymol solid surface representations of binding mode of N3 compound (A), Lymecycline (B) and Mizolastine (C). Representation of N3 (D), Lymecycline (E) and Mizolastine (F) predicted binding pockets using Dogsitescorer server. Amino acid residues are labeled: $\mathrm{N}$ (Gln) and $\mathrm{H}$ (His). 


\section{DISCUSSION}

The outbreak of a novel coronavirus (COVID-19) infections in 2019 is in dire need of finding potential therapeutic agents. In the following study, we choose eight drugs with antimalarial, anti-infective, antiviral proprieties. Since coronavirus are relatively large virus, which may be neutralized by drugs directed against parasites, bacteria or other large invectives micro-organisms. Mizolastine and Cetirizine antihistamine agents are included in this study because COVID-19 disease is characterized by a severe acute respiratory syndrome (SARS), which may be treated by anti-histamine drugs.

During our study, we simulated the binding mode of N3 against 6Lu7 crystal structure using SwissDock to ensure the effectiveness of docking results and to compare results produced by several drugs to those of N3. Indeed, this compound is a well characterized inhibitor of COVID-19 main protease.

Docking results revealed that N3, Indinavir, Chloroquine had the best energies of binding $-10.83,-9.81$ and $-9.71 \mathrm{Kcal} / \mathrm{mol}$, respectively, which is in consistence with three studies. The fist one reported the entire complex $\mathrm{N} 3 / \mathrm{CoV} \mathrm{M}^{\text {pro }}$ structure saved in the PDB database under 6Lu7 accession number [11]. The second reported that Indinavir presented a best docking score with a minimum energy of $-10.41 \mathrm{Kcal} / \mathrm{mol}$ using the Autodock Vina tool [12] and the last one based on molecular docking of anti-malarial agents against $6 \mathrm{Lu} 7$ crystal structure, which revealed that Chloroquine bind to $\mathrm{CoV} \mathrm{M}^{\text {pro }}$ with $-8.15 \mathrm{Kcal} / \mathrm{ml}$ binding energy [14].

Lymecycline and Mizolastine showed comparable binding energies of -8.87 and -8.71 $\mathrm{Kcal} / \mathrm{mol}$. It has been reported that Azelastine can undergo an optimal binding with $\mathrm{CoV} \mathrm{M}^{\text {pro }}$ [22]. When the clusters were analyzed it was found that N3, Indinavir, Chloroquine and Mizolastine showed that all clusters were able to fit into $\mathrm{M}^{\text {pro }}$ binding pocket. However, Lymecycline was able to occupy 23 clusters constituting a total of 168 possible conformations within the substrate binding cavity, out of a total of 256 elements. It is striking that all or more than half of the total predicted elements are docked in the substrate binding pocket.

Lymecycline and Mizolastine established $3 \mathrm{H}$-bonds in comparison with N3 which forms multiple hydrogen bonds with the main chain of residues in the substrate-binding pocket [11]. However, only two hydrogen bonds were detected after SwissDock analysis because the complex of $\mathrm{CoV} \mathrm{M}^{\text {pro }}$ with its inhibitor $\mathrm{N} 3$ was obtained in theoretical (in silico) not in experimental conditions.

Although Lymecycline and Doxycycline belong to the same family of tetracyclines, Lymecycline bind more effectively to $\mathrm{CoV} \mathrm{M}^{\text {pro }}$ with a minimum energy of $-8.87 \mathrm{Kcal} / \mathrm{mol}$ compared to Doxycycline with $-7.52 \mathrm{Kcal} / \mathrm{mol}$ binding energy, suggesting, the role of $\mathrm{NH}$ $(\mathrm{CH} 2)_{4} \mathrm{CH} \mathrm{COOH} \mathrm{NH} 2$ chemical substituting group in increasing the binding affinity of Lymecycline towards $\mathrm{CoV} \mathrm{M}^{\mathrm{pro}}$.

Lymecycline is a tetracycline broad-spectrum antibiotic. It is approximately 5000 times more soluble at all physiological $\mathrm{pH}$ values than tetracycline base and is unique amongst tetracyclines in that it is absorbed by the "active transport" process across the intestinal wall. 
Lymecycline presents a very good bioavailability (100\%) after oral administration and had a lipophilic nature. Thus, it can easily pass through the cell membrane. More importantly, Lymecycline had a safety profile comparable to Chloroquine which, represent a risk of cardiac arrest [23]. Otherwise, Mizolastine is non-sedating second generation anti-histamine, have a lower penetration of blood brain barrier and is less likely to cause drowsiness or psychomotor impairment. Therefore, Lymecycline may be associated to Mizolastine to fight COVID-19 infection [24]. 


\section{CONCLUSION}

We report the optimal binding of Lymecycline and Mizolastine with the main protease of SARS-CoV-2 using molecular docking study. However, this data need further in vitro and in vivo evaluation to repurpose these two drugs against COVID-19 disease. 


\section{References}

[1] Gorbalenya AE, Baker SC, Baric RS. The species Severe acute respiratory syndromerelated coronavirus: classifying 2019-nCoV and naming it SARS-CoV-2. Nat Microbiol ,2020; 5:536-44.

[2] Kupferschmidt K, Cohen J. Will novel virus go pandemic or be contained? Science, 2020; 367 (6478): $610-611$.

[3] Rodríguez-Morales A J, MacGregor K, Kanagarajah S, Patel D, Schlagenhauf P. Going global-Travel and the 2019 novel coronavirus. Travel Med Infect Dis, 2020; 33: 101578.

[4] Anthony SJ, Johnson CK, Greig DJ, Kramer S, Che X, Wells H, Hicks AL, Joly DO, Wolfe ND, Daszak P, Karesh W, Lipkin WI, Morse SS, Mazet JAK, Goldstein T. Global patterns in coronavirus diversity. Virus Evol, 2017 ; 3 (1): vex012.

[5] Zhou P, Yang XL, Wang XG, Hu B, Zhang L, Zhang W, Si HR, Zhu Y, Li B, Huang CL, Chen HD, Chen J, Luo Y, Guo H, Jiang RD, Liu MK, Chen Y, Shen XR, Wang X, Zheng XS, Zhao K, Chen QJ, Deng F, Liu LL, Yan B, Zhan FX, Wang YY, Xiao G, Shi ZL.. Discovery of a novel coronavirus associated with the recent pneumonia outbreak in humans and its potential bat origin. BioRxiv, 2020.

[6] Wu, F., Zhao, S., Yu, B., Chen, Y. M., Wang, W., Song, Z. G., Hu Y, Tao ZW, Tian JH, Pei YY, Yuan ML, Zhang YL, Dai FH, Liu Y, Wang QM, Zheng JJ, Xu L, Holmes EC, Zhang YZ. A new coronavirus associated with human respiratory disease in China. Nature, 2020; 579 (7798): 265-269.

[7] Kucharski AJ, Russell TW, Diamond C, Liu Y, Edmunds J, Funk S, Eggo R, Davies, N. Early dynamics of transmission and control of COVID-19: a mathematical modelling study. The Lancet Infect Dis, 2020.

[8] Liu C, Zhou Q, Li Y, Garner LV, Watkins S P, Carter LJ, Smoot J, Gregg AC, Daniel AD, Jervey S, Albaiu, D. Research and development on therapeutic agents and vaccines for COVID-19 and related human coronavirus diseases. 2020

[9] Anand, K., Ziebuhr, J., Wadhwani, P., Mesters, J. R., Hilgenfeld, R. (). Coronavirus main proteinase (3CLpro) structure: basis for design of anti-SARS drugs. Science, 2003; 300 (5626) : 1763-1767.

[10] Needle, D., Lountos, G. T., Waugh, D. S. Structures of the Middle East respiratory syndrome coronavirus 3C-like protease reveal insights into substrate specificity. D Biol. Crystallogr, 2015; 71(5): 1102-1111.

[11] Jin Z, Du X, Xu Y, Deng Y, Liu M, Zhao Y, Zhang B, Li X, Zhang L, Peng C, Duan Y, Yu J, Wang L, Yang K, Liu F, Jiang R, Yang X, You T, Liu X, Yang X, Bai, F, Liu H, Liu X, Luke WG, Xu W, Xia G, Qin C, Shi Z, Jiang H, Rao Z, Yang H. Structure of $\mathrm{M}^{\text {pro }}$ from COVID-19 virus and discovery of its inhibitors. bioRxiv, 2020. 
[12] Chang YC, Tung YA, Lee KH, Chen TF, Hsiao YC, Chang HC, Hsieh TT, Su CH, Wang SS, Yu JY, Shih SH, Lin YH, Lin YH, Tu YCE, Hsu CH, Juan HF, Tung CW, Chen CY. Potential therapeutic agents for COVID-19 based on the analysis of protease and RNA polymerase docking. 2020.

[13] Khaerunnisa S, Kurniawan H, Awaluddin R, Suhartati S, Soetjipto S. Potential Inhibitor of COVID-19 Main Protease (M pro) from Several Medicinal Plant Compounds by Molecular Docking Study. Prepr, 2020; 1-14.

[14] Srivastava AK, Kumar A, Tiwari G, Kumar R, Misra N. In Silico Investigations on the Potential Inhibitors for COVID-19 Protease. arXiv preprint arXiv:2003.10642, 2020.

[15] Wishart DS, Knox C, Guo AC, Shrivastava S, Hassanali M, Stothard P, Chang Z, Woolsey J. DrugBank: a comprehensive resource for in silico drug discovery and exploration. Nucleic Acids Res, 2006, 34; 668-672.

[16] Bernstein FC, Koetzle TF, Williams GJ, Meyer Jr EF, Brice MD, Rodgers JR, Kennard O, Shimanouchi T, Tasumi, M. The Protein Data Bank: A computer-based archival file for macromolecular structures. Eur J Biochem, 1977; 80(2): 319-324.

[17] Grosdidier A, Zoete V, Michielin O. SwissDock, a protein-small molecule docking web service based on EADock DSS. Nucleic Acids Res, 2011; 39: 270-277.

[18] Pettersen EF, Goddard TD, Huang CC, Couch GS, Greenblatt DM, Meng EC, Ferrin TE. UCSF Chimera a visualization system for exploratory research and analysis. $J$ comput chem., 2004; 25(13): 1605-1612.

[19] DeLano W. Pymol: An open-source molecular graphics tool, CCP4 Newsletter on protein. Crystallogr, 2002; 40:82-92.

[20] Salentin S, Schreiber S, Haupt VJ, Adasme MF, Schroeder M. PLIP: fully automated protein-ligand interaction profiler. Nucleic Acids Res, 2015;43, 443-447.

[21] Volkamer A, Kuhn D, Grombacher T, Rippmann F, Rarey M. Combining global and local measures for structure-based druggability predictions. J. Chem Inf Model, 2012; 52: 360-372.

[22] Odhar HA, Ahjel SW., Albeer AAMA., Fadhil A, Hashim AMR, Humadi SS. Molecular docking and dynamics simulation of FDA approved drugs with the main protease from 2019 novel coronavirus. Bioinformation, 2020;16(3) : 236-244.

[23] Protein Data Bank Database.

https://www.drugbank.ca/drugs/DB00256.

[24]PubChem Database.

https://pubchem.ncbi.nlm.nih.gov/compound/Mizolastine\#section=ATC-Code 


\section{Conflict of interest}

The authors declare no conflict of interest 